\title{
THE EFFECT OF OPERATIONS CASH, NET PROFIT, AND DEBT TOWARD THE DEVIDENTIC POLICY ON MANUFACTURING COMPANIES LISTED ON INDONESIA STOCK EXCHANGE
}

\author{
By: \\ Suryani \\ Suradi \\ Ratna Wulandari \\ Program Studi Administrasi Bisnis, Universitas Tulang Bawang Lampung \\ e-Mail: suryani_mr@yahoo.com
}

\begin{abstract}
This study aims to determine the influence of operation cash flow, net profit, and debt toward the devidentic policy on manufacturing companies listed on the Indonesia Stock Exchange. The research population is manufacturing companies listed on Indonesia Stock Exchange, and continues to distribute dividends to shareholders during the observation period 2015-2018. The sampling technique used in this study is the purposive sampling method and based on the technique, the number of samples that meet the requirements is 10 companies with a period of 4 years (2015-2019), so the number of samples is 40 companies. The analytical method used is Multiple Linear Regression Analysis.

The results of study are 1) based on the results of the T Test, the T calculated operation cash flow is 3,026 because the value of T arithmetic $3.026>T$ table 1.69 then Ho or the first hypothesis is rejected, it means that there is a partial influence between operation cash flow and dividend policy, 2) based on the results of the T Test, $T$ calculate net profit obtained by -1,451 because the value of T count $-1.451<T$ table 1.69 then Ho or the first hypothesis is accepted, it means that there is no partial influence between net profit and dividend policy, 3) based on the results of the T-Test, the T-calculated debt obtained by -1,241 because the value of $T$ count $1,241<T$ table 1.69 then Ho or the first hypothesis is accepted, it means that there is no partial influence between debt and dividend policy, and 4) based on the F Test, the F calculated independent variable is 6.115 because the $F$ value is $6.115>F$ table 2.87, Ho or the first hypothesis is rejected, it means that there is a simultaneous influence between operation cash flow, net profit, and debt toward the devidentic policy.
\end{abstract}

Keywords: operation cash flow, net profit, debt, and dividend policy 


\section{INTRODUCTION}

In principal, stock markets lie at the heart of financial systems. From a theoretical perspective, stock markets can accelerate economic growth by mobilizing and boosting domestic savings and improving the quality and quantity of investment. The basic function of stock markets is to serve as a mechanism for transforming savings into financing for the real sector. Better savings mobilization may increase the rate of saving and if stock markets allocate savings to investment projects yielding higher returns, the increasing rate of return to savers will make savings more attractive. Efficient stock markets make corporations compete on an equal basis for funds and help make investment more efficient. Consequently, more savings will be channeled into the corporate sector.

In certain situations, companies use debt to meet their funding needs. But companies must be careful and pay close attention to the impact caused by debt policy (Riyanto, 2001: 23).

In addition to using debt, companies can also obtain funds from the public by selling shares through the Indonesia Stock Exchange. The use of capital resources originating from investors, will cause the obligation to pay dividends. Theoretically, a company that has a high net profit will share a large dividend. But in practice, a company that has a large profit will not necessarily distribute a large amount of dividends because the company can use part of the profits obtained as retained earnings to develop the company (Acmad Noviyanto, 2016: 3).

Indonesia Stock Exchange is a stock exchange based in Jakarta. It was previously known as Jakarta Stock Exchange before its name changed in 2007 after merging with the Surabaya Stock Exchange. As of October 2019, the
Indonesia Stock Exchange had 656 listed companies with total market capital of USD 523 Billion (February 2019) and volume for IDR 11,11 trillion/day (2017).

\section{METHOD}

\section{Types of Data}

The type of data obtained in this study is secondary data. Namely research data obtained indirectly by researchers, but through the publication of the Indonesia Stock Exchange on its website www.idx.co.id.

\section{Population and Sample}

The population in this study were manufacturing companies listed on the Indonesia Stock Exchange in 2015-2018, totaling 201. Companies that were sampled amounted to 10 which were determined using the purposive sampling method.

\section{Research Variables}

The variables in this study include three independent variables, namely operating cash flow (X1), net profit (X2) and debt (X3) and the dependent variable, namely dividend policy (Y).

\section{Data Analysis Method}

The analytical tool used in this study is multiple linear regression with SPSS (Statistical Package for Social Science) program tools.

The multiple linear regression model is as follows:

$\mathbf{Y}=\mathbf{a}+\mathbf{b}_{1} \mathbf{X}_{1}+\mathbf{b}_{2} \mathbf{X}_{2}+\mathbf{b}_{3} \mathbf{X}_{3}+\mathbf{e}$

Means :

$\mathrm{Y}=$ Dividend Policy

$\mathrm{a}=$ constant

$b_{1}, b_{2}, b_{3}=$ regression coefficient

$\mathrm{X}_{1}=$ Operating Cash Flow

$\mathrm{X}_{2}=$ Net Profit

$\mathrm{X}_{3}=$ Debt

$\mathrm{e}=$ error 


\section{DISCUSSION}

\section{Test Model}

Table 1

Multiple Linear Regression Results

\begin{tabular}{|c|c|c|c|c|c|c|c|c|c|c|}
\hline \multicolumn{11}{|c|}{ Coefficients $^{a}$} \\
\hline \multirow[t]{2}{*}{ Model } & \multicolumn{2}{|c|}{$\begin{array}{l}\text { Unstandardized } \\
\text { Coefficients }\end{array}$} & \multirow{2}{*}{\begin{tabular}{|l|l|}
$d$ & $\begin{array}{l}\text { Standardized } \\
\text { Coefficients }\end{array}$ \\
or & Beta
\end{tabular}} & & \multirow[t]{2}{*}{ Sig. } & \multicolumn{3}{|c|}{ Correlations } & \multicolumn{2}{|c|}{$\begin{array}{l}\text { Collinearity } \\
\text { Statistics }\end{array}$} \\
\hline & $B$ & Std. Error & & & & $\begin{array}{l}\text { Zero- } \\
\text { order }\end{array}$ & Partial & Part & Tolerance & VIF \\
\hline (Constant) & .840 & 2.908 & & .289 & .774 & & & & & \\
\hline$X_{1}$ & .401 & .133 & .728 & 3.026 & .005 & .524 & .450 & .410 & .318 & 3.148 \\
\hline$1 \longdiv { X 2 }$ & .194 & .134 & .343 & -1.451 & .155 & .322 & .235 & .197 & .329 & 3.036 \\
\hline$x_{3}$ & .390 & .314 & .185 & -1.241 & .223 & .358 & .202 & .168 & .826 & 1.211 \\
\hline
\end{tabular}

Provided that if $\mathbf{T}$ arithmetic $>\mathbf{T}$ table then Ho or the first Hypothesis is rejected and $\mathrm{Ha}$ or the second hypothesis is accepted, and vice versa. So based on the provisions and table 4.1 the results are:

\section{Operating Cash Flow}

Ho is rejected and $\mathrm{Ha}$ is accepted, it means that there is an influence between operating cash flow on the dividend policy in a partial way.

\section{Net Profit}

Ho is accepted and Ha is rejected, it means that there is no influence between net income on dividend policy partially.

\section{Debt}

Ho is accepted and Ha is rejected, it means that there is no influence between debt and dividend policy partially.

\section{Table 2}

\begin{tabular}{|c|c|c|c|c|c|c|}
\hline \multicolumn{7}{|c|}{ ANOVAa } \\
\hline \multicolumn{2}{|r|}{ Model } & \multirow{2}{*}{\begin{tabular}{|c|} 
Sum of Squares \\
16.074 \\
\end{tabular}} & \multirow{2}{*}{$\begin{array}{c}\mathrm{Df} \\
3\end{array}$} & \multirow{2}{*}{$\begin{array}{c}\text { Mean Square } \\
5.358\end{array}$} & \multirow{2}{*}{$\begin{array}{c}\mathrm{F} \\
6.115\end{array}$} & \multirow{2}{*}{$\begin{array}{l}\text { Sig. } \\
.002^{\mathrm{b}}\end{array}$} \\
\hline \multirow{3}{*}{1} & Regression & & & & & \\
\hline & Residual & 31.540 & 36 & .876 & & \\
\hline & Total & 47.614 & 39 & & & \\
\hline \multicolumn{7}{|c|}{ a. Dependent Variable: $Y$} \\
\hline \multicolumn{7}{|c|}{ b. Predictors: (Constant), X3, X2, X1 } \\
\hline
\end{tabular}

Table 2 shows the calculated $F$ value of $6.115>\mathrm{F}$ table $=2.87(\alpha=0.05$, numerator variable number -1$)=4-1=3$ and denumerator (number of cases number of variables) $=40-4=36$.

It means that $\mathrm{Ho}$ or the first hypothesis is rejected. It means that simultaneously there is an influence of operating cash flow, net income, and debt on dividend policy.

Table 3

\begin{tabular}{|c|c|c|c|c|c|c|c|c|c|}
\hline \multirow[t]{2}{*}{ Model } & \multirow[t]{2}{*}{ R } & \multirow{2}{*}{\begin{tabular}{|l}
$\mathrm{R}$ \\
Square
\end{tabular}} & \multirow{2}{*}{$\begin{array}{l}\text { Adjusted } \\
\text { R Square }\end{array}$} & \multirow{2}{*}{$\begin{array}{l}\text { Std. Error } \\
\text { of the } \\
\text { Estimate }\end{array}$} & \multicolumn{4}{|c|}{ Change Statistics } & \multirow{2}{*}{$\begin{array}{l}\text { Durbin- } \\
\text { Watson }\end{array}$} \\
\hline & & & & & \begin{tabular}{|l|}
$R$ \\
Square \\
Change
\end{tabular} & F Change & $d f_{1}$ & $d f_{2}$ & \\
\hline 1 & $.581^{a}$ & 338 & 282 & .936015 & 338 & 6.115 & 3 & 36 & 1.037 \\
\hline
\end{tabular}

Table 3 obtained Adjusted R Square of 0.282 which means that the three dependent variables are only able to explain $28.2 \%$ of the Dividend Policy (DPR), while the remaining $71.8 \%$ is explained by other variables outside this study.

\section{CONCLUSION}

This study produces the following conclusions:

1. Based on the results of the $T$ Test, the T calculated operating cash flow is 3,026. Because the value of $\mathrm{T}$ arithmetic 3.026> $\mathrm{T}$ table 1.69 then Ho or the first hypothesis is rejected. It means that there is a partial influence between operating cash flow on dividend policy.

2. Based on the results of the $T$ Test, $\mathrm{T}$ calculate net income obtained by 1,451 . Because the value of $T$ count -1.451 $<\mathrm{T}$ table 1.69 then $\mathrm{Ho}$ or the first hypothesis is accepted. It means that there is no partial effect between net income on dividend policy.

3. Based on the results of the TTest, the T-calculated debt obtained by 1,241 . Because the value of $T$ count $-1,241$ $<\mathrm{T}$ table 1.69 then $\mathrm{Ho}$ or the first hypothesis is accepted. It means that there is no partial effect between debt and dividend policy.

4.Based on the $\mathrm{F}$ Test, the $\mathrm{F}$ calculated independent variable is 6.115 . Because the $\mathrm{F}$ value is $6.115>\mathrm{F}$ table 2.87, Ho or the first hypothesis is rejected. It means that there is a simultaneous influence 
between operating cash flow, net income, and debt on dividend policy.

Suggestions that can be given from the results of this study are:

To minimize the dividend policy that can harm various parties, further review of the factors that influence the size of the dividend to be paid by the company is needed. Therefore, this research and previous research and also future studies can be references of company in making decisions regarding dividend policy.

Due to this research is limited to only three dependent variables namely operating cash flow, net profit, and debt, it is recommended that further researchers will add the dependent variable.

Further researchers are advised to be able to conduct research with other models and methods so they can know dividend policy more accurately.

Further researchers are also strongly advised to conduct research in other company sectors and increase the period of the research year so that a clearer dividend policy will be obtained.

\section{REFERENCES}

Achmad, Noviyanto. 2016. Pengaruh Laba Bersih, Arus Kas Operasi, Dan

Likuiditas Terhadap Kebijakan

Dividen. 2 Jurnal Profit. Edisi 8.

Alghifari. 2002. Analisis Regresi (Teori, Kasus dan Solusi). Edisi Kedua.

Yogyakarta : BPFE.

Apriliani, Amalia dan Kartina

Natalylova. 2017. Faktor-Faktor Yang

Mempengaruhi Kebijikan Deviden Pada

Perusahaan Manufaktur di Bursa Efek

Indonesia. Jakarta : STIE Trisakti

Atmaja, Lukas Setia. 2008. Manajemen

Keuangan. Penerbit Andi : Yogyakarta.

Bansaleng, Resky D.V, Parengkuan Tomy dan Ivonne S. Saerang. 2014.
Kebijakan Hutang, Struktur Kepemilikan dan Profitabilitas Terhadap Kebijakan Dividen Pada Perusahaan Food and Beverage di Bursa Efek Indonesia. Fakultas Ekonomi dan Bisnis Jurusan Manajemen Universitas Sam Ratulangi. Manado.

Brigham, Eugene F. and Besley, Scott. 2005. Essential Of Managerial Finance. USA.

Chariri, dan Imam Ghazali. 2011. Teori Akuntanai. Semarang : Badan Penerbit UNDIP.

Dewi, Hayuningtyas. P. 2015. Pengaruh Perputaran Piutang Dan Hutang Terhadap Arus Kas Operasi. Studi Pada PT. Exer Indonesia. Skripsi. Universitas Dwipayana. Jakarta.

Fahmi, Irham. 2012. Analisis Kinerja Keuangan. Bandung: Alfabeta.

Ghozali. 2016. Aplikasi Analisis Multivariete Dengan Program IBM SPSS. Semarang: Badan Penerbit Universitas Diponegoro.

Gitman, Lawrence J dan Chad J. Zutter. 2012. Principles of Managerial Finance.

13th Edition.Global Edition: Pearson Education Limited.

Gujarati, D.N. 2012. Dasar-dasar Ekonometrika. Terjemahan Mangunsong, R.C.

Buku 2. Edisi 5. Jakarta : Salemba Empat

Harahap. 2007. Analisis Kritis Atas Laporan Keuangan. Edisi Pertama. Cetakan Ketiga. Jakarta : Raja Grafindo Persada.

Harahap, Sofyan Syafri. 2016. Teori Akuntansi. Edisi Revisi 2011. Jakarta : PT. Rasa Grafindo Persada.

Hasan, M. Iqbal. 2002. Pokok-pokok Materi Metodologi Penelitian dan 
Aplikasinya, Ghalia Indonesia.

Bogor.

Ikatan Akuntansi Indonesia. 2009.

Pernyataan Standar Akuntansi

Keuangan. PSAK. Jakarta: Penerbit

Salemba Empat.

Irawan, David dan Nurdhiana. 2012.

Pengaruh Laba Bersih dan Arus

Kas Operasi Terhadap Kebijakan

Deviden. Semarang : STIE Widya

Manggala.

Kumparan.com/iklan-mitoz/perusahaan-

manufaktur-dan-pengertiannya.

Kuncoro, Mudrajat. 2011. Metode Kuantitatif. Yogyakarta: Sekolah Tinggi Ilmu Manajemen: YKPN.

Lisa, Marlina, dan Clara Danica. 2009. Analisis Pengaruh Cash Position, Debt To Equity Ratio, Dan Return On Assets Terhadap Dividen Payout Ratio. Jurnal Manajemen Bisnis. Vol. 2.No. 1.Januari 2009.

L.M. Syamryn. 2011. Pengantar Akuntansi. Jakarta : PT. Grafindo Persada.

Muhammad Gade. 2005. Teori Akuntansi. Jakarta :Almahira.

Mulyaningsih, Nining dan Dwi Rahayu. 2016. Pengaruh Laba Bersih dan Arus Kas Operasi Terhadap Kebijakan Deviden Pada Perusahaan Food and Beverage Yang Terdaftar di Bursa Efek Indonesia.. Semarang : STIE Dharmaputra.

Manurung, dan Siregar. 2009. Pengaruh Laba Bersih dan Arus Kas Operasi Terhadap Kebijakan Deviden. Jurnal Akuntansi :Universitas Sumatera Utara.

Munawir. 2017. Analisa Laporan Keuangan. Edisi Keempat. Yogyakarta:Liberty.

PSAK nomor 2. Tentang Laporan Arus Kas. Edisi Revisi 2015.

Rahmaniar, Ani dan Soegijanto. 2016. Pengantar Akuntansi Dasar 1. Bogor : In
Media.

Rasyid. 2011. Hubungan Laba Bersih, dan Arus Kas Operasi dengan Deviden.

Jurnal Akuntasi Tahun V. Vol.1. Mei 2011 : Universitas Tarumanegara.

Riyanto, Bambang. 2001. Dasar-dasar Pembelanjaan Perusahaan. Yogyakarta :

BPEE Yayasan Badan Penerbit Gajah Mada.

Rudianto. 2012. Pengantar Akuntansi. Jakarta : Penerbit Erlangga Adaptasi IFRS.

Santoso, Singgih.2010. Statistik Parametrik, Konsep dan Aplikasi dengan SPSS.

Cetakan Pertama, PT Elex Media Komputindo, Jakarta : PT Gramedia, 2012. Panduan Lengkap

SPSS Versi 20. Jakarta: PT Elex Media Komputindo.

Sodikin, Slamet Sugiri dan Boget Agus Riyono. 2014. Akuntansi Pengantar 1.

Edisi Kesembilan. Yogyakarta :

Unit Penerbit dan Percetakan Sekolah Tinggi Ilmu Ekonomi YKPN

Stice, et al. Akuntansi Keuangan Menengah, Edisi 16, Buku 2. Edisi Bahasa Indonesia. Terjemah Oleh Ali Akbar. Jakarta : PT. Salemba Empat.

Sudjana. 2003. Teknik Analisis Regresi dan

Korelasi bagi Peneliti.

Bandung :Tarsito.

Sugiyono. 2012. Metode Penelitian Kuantitatif Kualitatif dan $R \& D$.

Bandung : Alfabeta.

2014. Metode Penelitian Pendidikan Pendekatan Kuantitatif, Kualitatif dan $R \& D$. Bandung: Alfabeta.

Suharli, M dan Oktarina, M. 2005. Memprediksi Tingkat Pengembalian Investasi pada Equity Securities Melalui Rasio Profitabilitas, Likuiditas, dan 
Hutang pada Perusahaan Publik di Jakarta.

Sulistyowati, Agnes, Suhadak dan Achmad.

2014. Pengaruh Struktur Modal

Terhadap Kebijakan Deviden. Jurnal Administrasi Bisnis (JAB).

Vol.8, No.2.

Suwardjono.

Scribd.com/doc/266602717/Signali ng-Theory.

Syafriadi. 2000. Kemampuan Earnings dan Arus Kas Masa Depan : Studi di Bursa Edek Indonesia Jakarta. Jurnal Bisnis dan Akuntansi. Vol.2. No.1.

Wild, John.J. 2009. Financial Statement Analysis. Terjemahan K. R.

Subramanyam. 2013 : Jakarta : Salemba Empat.

Wild, John J, K. R. Subramanyam, Robert F. Halsey. 2005. Analisis Laporan

Keuangan. Edisi 8.Buku 2.Jakarta : Salemba empat.

Weston, J.Fred, dan Thomas E. Copeland. 2010. Manajemen Keuangan. Edisi

Revisi. Jakarta : Binarupa Aksara Publisher.

Weygandt, Jerry. J, Donald E. Kieso, and Paul D. Kimmel. 2011. Pengantar Akuntansi. Edisi 7.Buku 2. Jakarta: Salemba Empat.

\section{a. Example source from text book:}

Harmer, Jeremy. (2007). How to teach Writing. Cambridge: Cambridge University Press.

Hyland K,. (2003). Second language Writing. Cambridge: Cambridge University Press

Anne, Burn. (2010). Doing Action Research in English Language Teaching: A guide for Practitioner. New York: Routledge.

\section{b. Summarized text book by editor .}

Sofian Effendi. (1982). Unsur-unsur penelitian ilmiah. Dalam Masri Singarimbun (Ed.). Metode penelitian survei. Jakarta: LP3ES.

\section{c. Translated book}

Daniel, W.W. (1980). Statistika nonparametrik terapan. (Terjemahan Tri Kuntjoro). Jakarta : Gramedia.

\section{d. Thesis and dissertation}

Slamet Suyanto (2009). Keberhasilan sekolah dalam ujian nasional ditinjau dari organisasi belajar. Disertasi, tidak dipublikasikan. Universitas Negeri Jakarta.

\section{e. Journal}

Gill, A. et al. (2010). The Relationship between Working Capital Management and Profitability: Eviden from The United State, Journal of Business and Economics. Volume 2010.

\section{f. Proceeding:}

Paidi. (2008). Urgensi pengembangan kemam-puan pemecahan masalah dan metakog-nitif siswa SMA melalui pembelajaran biologi. Prosiding, Seminar dan Musyawarah Nasional MIPA yang diselenggarakan oleh FMIPA UNY, tanggal 30 Mei 2008. Yogyakarta: Universitas Negeri Yogyakarta.

\section{g. Internet}

White, H. (2007). Problem-based learning in introductory science across disciplines. Diakses tanggal 27 Maret 2007 dari http://www.udel.edu/chem/white/fi nalrpt.htm 